\title{
A poética mística de Adélia Prado
}

Enviado em: 16/09/2018

Aceito em: 05/03/2019

Resumo: Este artigo reflete sobre a obra poética de Adélia Prado e suas articulações com alguns aspectos da espiritualidade cristã. Para alcançar este objetivo, busca primeiramente estabelecer relações entre sua concepção mística de poesia, com algumas proposições de pensadores da cultura ocidental, especialmente quanto à ideia do Logos: Tomás de Aquino, importante filósofo cristão, e Heráclito, pensador grego, anterior à era cristã. Após identificar essas aproximações filosóficas, a análise recorre a considerações teóricas de Teilhard de Chardin, teólogo católico de meados do século XX, para compreender o significado da noção de alegria, associada à fé cristã e abordada, direta ou indiretamente, em muitos poemas da autora. Além disso, assinala diálogos intertextuais que a obra poética adeliana estabelece com textos bíblicos neo e veterotestamentários. Recorre, ainda, a textos utilizadas por Adélia Prado em seu primeiro livro, Bagagem (1976), que reforçam sua opção pela teologia católica, dialogando especialmente com o pensamento de Francisco de Assis. A partir dessas considerações, o artigo aponta para o fato de que aspectos da religiosidade cristã se tornaram características de algumas expressões da poesia modernista brasileira, de acordo com observações críticas de Augusto Massi (2015).

Palavras-chaves: Adélia Prado; Poesia; Mística Cristã.

Abstract: This article reflects on the poetic work of Adélia Prado and its articulations with some aspects of Christian spirituality. In order to achieve this goal, he seeks first to establish relations between his mystical conception of poetry and some propositions of Western thinkers, especially concerning the idea of the Logos: Thomas Aquinas, an important Christian philosopher, and Heraclitus, a Greek thinker, prior to the Christian era. After analyzing these philosophical approaches, the analysis draws on the theoretical considerations of Teilhard de Chardin, a Catholic theologian of the mid-twentieth century, to understand the meaning of the notion of joy associated with the Christian faith and addressed, directly or indirectly, in many of the author's poems. In addition, it marks intertextual dialogues that the poetic Adélia's work establishes with biblical texts of the New and the Old Testament. He also recalls texts used by Adélia Prado in his first book, Bagagem (1976), which reinforce his choice for Catholic theology, especially in the words of Francis of Assisi. From these considerations, the article points to the fact that aspects of Christian religiosity have become characteristic of some expressions of Brazilian modernist poetry, according to critical observations by Augusto Massi (2015).

Keywords: Adélia Prado; Poetry; Christian Mysticism.

Adélia Prado explicita uma visão de mundo que alia o cotidiano e sua experiência mística, em muitos de seus depoimentos e entrevistas:

\footnotetext{
${ }^{1}$ Doutoranda em Letras pelo Programa de Pós-Graduação em Letras da Universidade Federal do Espírito Santo (UFES) e bolsista pela CAPES. Integra o Grupo de Pesquisa "Mulheres com todas as letras", coordenado pela Profa. Dra. Maria Mirtis Caser. Estuda a obra poética de Adélia Prado.
} 
Minha insistência no cotidiano é porque a gente só tem ele: é muito difícil a pessoa se dar conta de que todos nós só temos o cotidiano, que é absolutamente ordinário (ele não é extraordinário). E eu tenho absoluta convicção de que é atrás, através do cotidiano, que se revelam a metafísica e a beleza; já está na Criação, na nossa vida (PRADO, 2008).

A partir da leitura de seus textos e de depoimentos como esse, percebe-se a intencionalidade da poeta de se ater ao cotidiano, de onde sua arte emerge em louvor à beleza do mundo e de onde se delineia o aspecto místico de sua poesia. Trata-se de uma ligação, a um só tempo, literária e existencial, como uma forma de espiritualidade que perpassa a realidade do dia a dia.

A sensibilidade de Adélia para se vincular ao imponderável, ao extraordinário nas coisas mais simples do cotidiano, aproxima a poeta de uma linha de pensamento que remonta a distintos filósofos em diversas épocas. Este artigo pretende refletir sobre as afinidades de seu pensamento com alguns desses pensadores.

O entendimento adeliano, de que existe uma realidade que perpassa o comum de todas as coisas, assinala uma conexão estreita entre sua poesia e as idéias de Tomás de Aquino. Adélia, inclusive, reconhece publicamente a influência desse pensador sobre o seu fazer poético.

Para Tomás de Aquino, Deus, o Logos eterno, existe por si mesmo, diferentemente de tudo o mais. Além disso, para esse pensador cristão, todas as coisas existem e subsistem em Deus e têm nele a sua causa:

[...] tendo Deus a existência idêntica à essência, o ser criado há de necessariamente ser efeito próprio seu, assim como queimar é efeito próprio do fogo. Ora, tal efeito Deus causa nas coisas, não somente quando começam a existir, mas enquanto subsistem; assim como a luz é causada no ar pelo sol, durante todo o tempo em que permanece iluminado. Logo, enquanto subsistir uma coisa, é necessário que Deus lhe esteja presente, conforme o modo de existência próprio dela. Ora, o ser é o que de mais íntimo tem uma coisa e o que de mais profundo existe em todas as coisas; pois, comporta-se como forma em relação a tudo o que na coisa existe, conforme no sobredito se colhe. Logo, é necessário que Deus esteja, e intimamente, em todas as coisas (AQUINO, 2017, p. 161).

Assim, todas as realidades naturais, perceptíveis e imperceptíveis, estão ligadas por codependência, a uma fonte original e vital, da qual fazem parte e que as sustenta e anima. Para Tomás de Aquino, essa fonte primeira seria Deus.

Essas proposições integram também o conceito de participação (Participatio) formulado por esse pensador cristão. Embora seja um conceito complexo, com variados desdobramentos, o que importa ressaltar no momento é que:

A doutrina da criação como participação traz consigo uma tensão dialética própria, entre o aspecto positivo e o negativo da dualidade da participação: a criatura participa, sim, do ser; mas a partir do nada [...] A mesma pedra que traz para nós, pelo olhar do artista, um plus - participa do ser e da bondade e da beleza de Deus - nos remete também a um nibil, ao nada, a partir do qual ela foi feita. Naturalmente, o aspecto mais evidente, em geral, nas artes, é o positivo, o da participação na beleza (LAUAND, 2011, p. 63).

Na obra de Adélia Prado, a concepção da participação do que é material na beleza do que é transcendental é um fundamento de sua poética. A poesia seria uma porta para acessar esse mistério, que não se divorcia do cotidiano e está presente em todas as coisas. Há no cotidiano, assim, uma ligação com o sagrado. Os fatos da existência humana presentes em 
seus versos são perpassadas pelo sagrado. Assim, experiência mística e fazer poético se fundem na sensibilidade de perceber a vibração divina de todas as coisas, nos acontecimentos cotidianos, os mais simples e corriqueiros.

Falando a respeito do que o pensamento humano manifesto em linguagem tem de relação com Deus, ao ser indagada se, no seu caso, a experiência e a poesia estão a serviço da fé, Adélia responde:

Para mim, experiência religiosa e experiência poética são uma coisa só. Isto porque a experiência que um poeta tem diante de uma árvore, por exemplo, que depois vai virar poema, é tão reveladora do real, do ser daquela árvore, que ela me remete necessariamente à fundação daquele ser. A origem, quer dizer, o aspecto fundante daquela experiência, que não é a árvore em si, é uma coisa que está atrás dela, que no fim é Deus, não é? (PRADO, 2000, p. 23).

Adélia Prado, nessa perspectiva, se vincula a uma concepção mística da poesia. Sobre essa concepção estética, Domingos Carvalho da Silva esclarece: "Há poetas que atribuem à poesia uma função mística e uma origem divina. Possuem uma visão filosófica do mundo e da existência humana, marcada pela crença numa alma imortal, individual e de origem divina, "hóspede' do corpo" (SILVA, 1986, p. 123).

Para Adélia, a poesia seria uma manifestação da linguagem, própria da nossa condição simbólica, que nos revela o real inominável, aquilo que é de verdade. Tal manifestação seria intrínseca à nossa impossibilidade de alcançar plenamente o divino, o mistério, seria uma "pegada de Deus", de cujo ente, tudo é participante, ainda que na forma bruta das coisas.

Dessa forma, Deus não é só a fonte de todo o real, mas também de todo fazer artístico. É o que percebemos sobre a perspectiva adeliana nos seguintes versos do poema "Paixão": "De vez. em quando Deus me tira a poesia./ Olho pedra e vejo pedra mesmo." (PRADO, 2015, p.146). Como manifestação divina, a poesia emerge da realidade cotidiana, pois o elemento desencadeador do discurso poético é a vontade e a presença divina. Sem a presença do mistério divino que perpassa todas as coisas, a realidade cotidiana cai em desencantamento, em estado de despoesia: a pedra não alcança (além do intertexto drummondiano) transcendência simbólica nem metafórica, isto é, não se revela em sua significação para a poeta.

Assim, no entender de Adélia, a ideia de poesia se mistura com seu perfil religioso, ligado à fé católica, adensado em toda a sua obra numa articulação entre sagrado e profano, religiosidade e erotismo, revelando aspectos inusitados do fazer poético associado ao misticismo.

Antes mesmo da percepção filosófica cristã sobre o Logos originário e sustentador de todas as coisas, o filósofo pré-socrático, Heráclito de Éfeso, que viveu aproximadamente entre 535 a.C. - 475 a.C., também acreditava na existência de algo primordial, permanente e unitário que explicaria a contínua transitoriedade manifesta pelas coisas comuns da experiência no mundo. O fragmento 31, dos possíveis fragmentos do livro Sobre a natureza, atribuído a esse pensador, traz estes dizeres: "Tropos do fogo: primeiro, mar; do mar, a metade terra, a metade vento ardente. O mar se estica de ponta a ponta e encontra sua medida de acordo com o mesmo Logos que era primeiro” (HERÁCLITO, 2005, p.67).

Para Heráclito e grande parte da tradição grega de seu tempo, a origem de tudo era o Logos, uma lógica racional primeira e determinante de todas as coisas. Mas, para o pensador grego, os seres humanos comuns, que não se exercitam na compreensão do que existe e acontece, não se apercebem dessa realidade original e una, presente em tudo na experiência humana, mas não necessariamente perceptível pelos sentidos imediatos: "Do Logos com que sempre lidam e se afastam, e por isso as coisas que encontram lhes parecem estranhas" 
(HERÁCLITO, 2005, p. 79).

Mantendo certa relação com essas idéias, Adélia Prado, ao interpretar a vida e a arte, entende que caberia ao poeta o papel de oráculo catalisador dessa sensibilidade para perceber a presença de algo superior, anterior e unificador de tudo, presença que seria, no dizer do pensador de Éfeso, o Logos primordial e uno em todas as coisas: "Auscultando não a mim, mas o Logos, é sábio concordar que tudo é um" (HERÁCLITO, 2005, p. 71).

Sendo assim, os versos de Adélia Prado mantêm estreita relação com a ideia de um Logos, que gera e sustenta todas as coisas criadas. Mas, na medida em que se apóia também em fundamentos teológicos de uma fé católica, o entende como o Deus dos cristãos.

É possível observar também como Adélia Prado dialoga com as escrituras bíblicas, ligadas tanto ao Novo quanto ao Velho Testamento, fontes de inúmeras conexões intertextuais que ela realiza, empreitando até mesmo, em vários momentos, a dessacralização de alguns dogmas da tradição judaico-cristã, principalmente pela via do erotismo. Como é perceptível nos versos do poema "Agora, ó José" (PRADO, 2015, p. 32-33), em que o ato amoroso se torna ato de redenção humana. Os versos dialogam ao mesmo tempo com os Evangelhos e os versos drummondianos dos poemas "No meio do caminho" e "E agora, José" (ANDRADE, 1988, p. 15; 88):

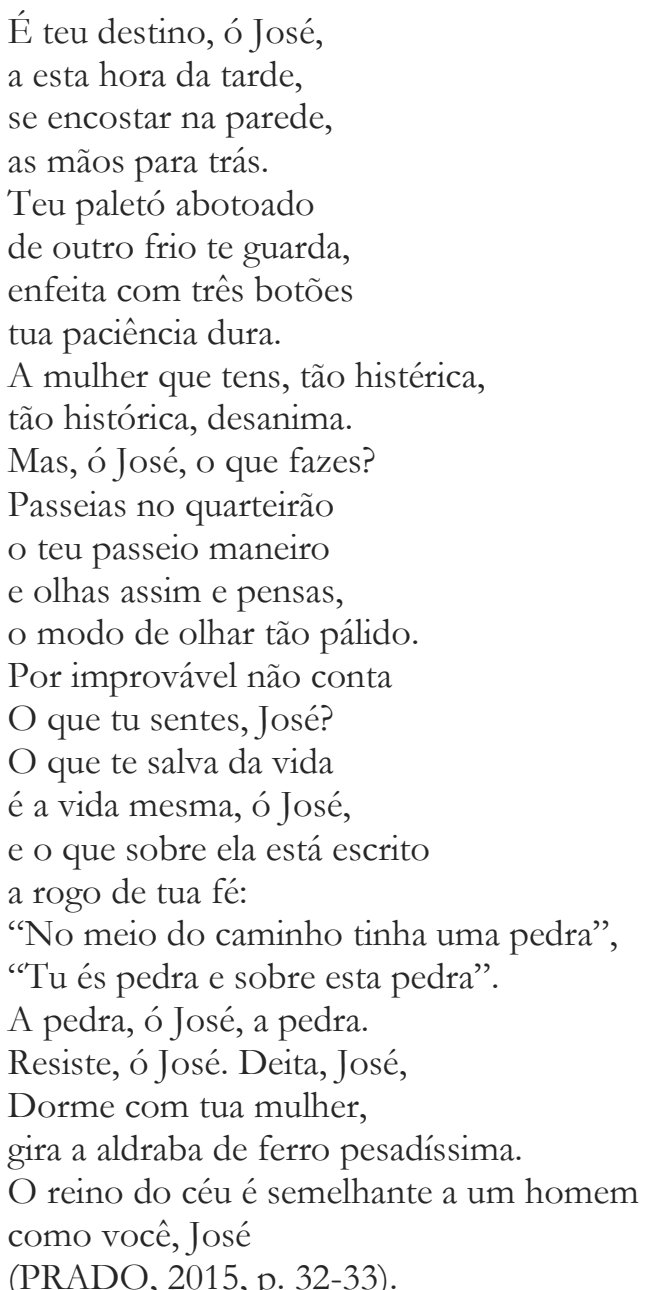

O poema adeliano reflete sobre o cotidiano de um homem simples: “É teu destino, ó José,/ a esta hora da tarde,/ se encostar na parede [...]”. Há uma rotina de vida. Mas essa 
rotina traz sinais de morte: "Teu paletó abotoado/ de outro frio te guarda [...]". Assim, o poema transcorre em fluxos e refluxos de vida e de morte, respectivamente. O tempo é o presente, o agora, e sobre esse agora da vida rotineira, os anúncios do destino de José e de todos repousam.

O que salva José dessa vida "é a vida mesma". É o que sobre ele está escrito, por Drummond ("No meio do caminho tinha uma pedra") e na Bíblia, trazendo à memória o episódio que aconteceu entre Jesus e Pedro, quando este, respondendo à pergunta do mestre sobre quem diziam que ele era, proferiu "Tu és o Cristo, o Filho do Deus vivo". Nos versos de Adélia, resta, a José, a mesma insígnia destinada à sentença de Pedro: "Tu és pedra e sobre esta pedra". O poema eleva, dessa forma, o verso de Drummond ao patamar de escritura sacra ("e que sobre ela está escrito/ a rogo de tua fé"). E, por fim, conclama José à resistência, já que pedra ("Resiste, ó José [...]”).

A maior resistência de José deve se dar no ato de dormir com sua mulher: "[...] Deita, José/ dorme com tua mulher". A convocação se estende ao imperativo de girar a aldraba de ferro, verso rico em lirismo e eroticidade, que remete ao ato sexual, dificultadíssimo e pesado, talvez pela rotina e pelo pouco desejo que o cotidiano impõe, talvez pela culpa e a dificuldade de abrir o corpo para o que lhe é próprio: o prazer corporal. Ao mesmo tempo, se relaciona a perceber e "abrir" a mulher para a descoberto e o usufruto do corpo.

Nesse trecho, Adélia intertextualiza com a escritura bíblica, agora veterotestamentária, no livro de Eclesiastes, capítulo 9, verso 9, trecho do mais pessimista dos livros bíblicos: "Goza a vida com a mulher que amas, todos os dias da tua vida vã, os quais Deus te deu debaixo do sol, todos os dias da tua vida vã; porque este é o teu quinhão nesta vida, e do teu trabalho, que tu fazes debaixo do sol" (BÍBLIA SAGRADA, 1993, p. 671).

Percebe-se, ainda, a dessacralização presente no último verso, em que o reino do céu se traduz em vida simples, de um homem como José, ao rés do chão. O reino do céu que se encarna, remetendo também à encarnação do Cristo, vivida entre realidades humanas simples e comuns.

Outro aspecto importante em muitos dos textos poéticos de Adélia Prado é um personagem recorrente, uma terceira pessoa lírica, chamada Jonathan. O nome tem origem no hebraico, Jehonathan, que é formado pela união dos elementos $Y_{0}$, que significa "Deus", "o Senhor" ou "Jeová", e nathán, que quer dizer "ele deu". Significa, portanto, "dado por Deus", "presente de Deus" ou "dádiva divina.

Jonathan é ao mesmo tempo personagem e interlocutor, com quem, ora o sujeito lírico de muitos poemas dialoga, ora partilha a relação amorosa. Torna-se por vezes uma encarnação do próprio Deus, à semelhança de Jesus Cristo, o Filho do Homem, o "masculino" cristão corporificado. Jonathan é a mais pura expressão adeliana da dessacralização do divino, como se percebe no poema "Sacrifício":

\footnotetext{
Não tem mar, nem transtorno político, nem desgraça ecológica que me afaste de Jonathan.

Vinte invernos não bastaram

pra esmaecer sua imagem.

Manhã, noite, meio-dia,

como um diamante,

meu amor se perfaz, indestrutível.

Eu suspiro por ele.

Casar, ter filhos,

foi tudo só um disfarce, recreio,
} 
um modo humano de me dar repouso.

Dias há em que meu desejo é vingar-me,

proferir impropérios: maldito, maldito.

Mas é a mim que maldigo,

pois vive dentro de mim

e talvez seja deus fazendo pantomimas.

Quero ver Jonathan

e com o mesmo forte desejo

quero adorar, prostrar-me,

cantar com alta voz Panis Angelicus.

Desde a juventude canto.

Desde a juventude desejo e desejo

a presença que para sempre me cale.

As outras meninas bailavam,

eu estacava querendo

e só de querer vivi.

Licor de romãs,

Sangue invisível pulsando na presença Santíssima.

Eu canto muito alto:

Jonathan é Jesus

(PRADO, 2015, p. 266).

Para Adélia, poesia é uma forma de oração, de dialogar com a divindade presente em todos os aspectos da vida e de forma singular na relação que mantém também, como voz feminina, com a voz masculina de Jonathan. Essa voz feminina, em seu sentido clássico, é expressão de uma relação com o outro, também com o masculino, na construção de realidades humanas. Pela invenção ou tradução corporal da divindade, a poeta, que vive num corpo com suas próprias leis, "encarna" sua vontade de absoluto na/por meio da presença de um ser divino desejável amorosamente.

Adélia Prado ainda se utiliza dos diálogos intertextuais com o pensamento de outros poetas místicos importantes da história da igreja cristã. Bagagem (1976), por exemplo, traz como epígrafe inicial uma paráfrase do Cântico das criaturas, de Francisco de Assis: "Louvai o Senhor, livro meu irmão, com vossas letras e palavras, com vosso sentido, com vossa capa e forma, com as mãos de todos que vos fizeram existir, louvai o Senhor" (PRADO, 2015, p. 13). O cântico franciscano foi composto em 1225 (BOFF, 2017). Trata-se de um canto de amor ao Criador e a todas as suas obras, onde suas criaturas são convocadas a lhe render louvores. Na tradição católica, Francisco de Assis é um santo que percebia o laço de fraternidade que une todos os seres criados. Com ternura, trata cada ser vivente, além de todos os luminares celestes e todos os fenômenos da natureza, como irmãos e irmãs.

$\mathrm{Na}$ epígrafe de Adélia, há a referência aos próprios poemas transformados em livro, produto da criação também das várias mãos que o editaram. Todos os envolvidos são chamados a louvar o Senhor. Com essa referência, a epígrafe torna-se mais do que uma convocatória, transforma-se em dedicatória, oferta litúrgica de gratidão. Além disso, aponta claramente para o viés religioso que permeará os versos da autora.

A primeira parte do livro, "O modo poético", traz também uma epígrafe, que explicita a relação da autora com a poesia e com a vida, apoiada em princípios que deixam também claros os seus fundamentos religiosos: "Chorando, chorando, sairão espalhando sementes. Cantando, cantando, voltarão trazendo os seus feixes. (Escrito nos salmos)" (PRADO, 2015, p. 15).

O texto epigráfico remete textualmente aos salmos bíblicos, mais especificamente ao 
"Salmo 126"2, que faz parte do grupo de salmos de romagem, dos "Cânticos de peregrinação"3, e trata do regresso de Israel do exílio em Babilônia. O povo judeu, antes exilado e sem esperança, alimentava agora a certeza de chegar à sua terra de origem. Alegremente cantava, tocava, sonhava construir casas, reerguer os muros da cidade. É um salmo pós-exílio, portanto. Os judeus experimentavam sua sonhada libertação, depois do cativeiro.

A correlação do fazer poético, sugerido no título da seção, com o pano de fundo da história bíblica, está indicada no paralelismo dos versos. A alegria proposta está relacionada a uma colheita de poesia ("cantando, cantando"), em meio ao sofrimento próprio da existência ("chorando, chorando"). Evidencia-se, assim, uma concepção de poesia para além da palavra escrita, que a inclui, mas que a transcende.

Trazendo essas referências, além da própria concepção do fazer poético, Adélia faz antever o aspecto mais caro ao seu modo poético: a estreita ligação de seus versos com convicções religiosas herdadas de uma fé católica, que se traduz em uma poesia também prenha de esperanças de uma vida pós-morte.

Sobre isso, Margarida Salomão afirma: "É impossível separar essas convicções teológicas da concepção de poesia em Adélia Prado: não há poesia sem a possibilidade da ressurreição da carne ('a poesia, a mais ínfima, é serva da esperança [...]')" (SALOMÃO, 1976, p.12). Seus poemas apontam, então, uma vontade de alegria permanente, que deverá ser experimentada após a morte, talvez como um estado pleno de felicidade e de poesia.

Para entendermos o que seria, talvez, aquilo a que os poemas adelianos se referem, tomemos por empréstimo o conceito de felicidade, segundo Pierre Teillhard de Chardin 4 . Essa escolha não é aleatória, uma vez que a própria Adélia reverencia esse pensador em suas entrevistas e depoimentos, o que nos sugere que o pensamento da poetisa se alinha com sua perspectiva. Isso também é observado por outros pesquisadores de sua obra. Por exemplo, José Francisco Navarro Huamán nota que Adélia não tem uma mística de distanciamento da matéria, mas sim de encontro com ela e que isso a aproxima de Chardin (HUAMÁN, 2000, p. 35). A própria Adélia confirma a observação:

Isso que você fala de Chardin me alegra demais. Muito antes de começar a escrever e publicar, eu li Teillhard de Chardin e fiquei espantada com o amor dele pela matéria. É uma maravilha. Ele fala da "cristificação" do mundo. Esse grão de areia faz parte do corpo de Cristo; então, está tudo restaurado em Cristo. Eu li e falei: "Esse é dos bons" (PRADO, 2000, p. 35).

\footnotetext{
2 O livro dos Salmos engloba um conjunto de 150 cânticos. Há uma diferenciação na numeração dos salmos, decorrente das versões hebraicas e gregas. A questão remonta à tradução do hebraico para o grego, antes de Cristo, a assim chamada LXX (Setenta). A LXX numerou de maneira diferente os Salmos. A V ulgata (versão latina) seguiu a numeração da $L X X$, muito difundida. Atualmente, usa-se mais a numeração original, aquela que está no texto hebraico, em que a numeração citada se baseia, mas há variações nas traduções para o Português (DAVIS, 1973, p. 528).

3 Esta é uma coleção de 15 Salmos (do 120 ao 134), também chamados de "Cânticos da Subida" ou de "Degraus". Essas canções foram usadas no período pós-exílio pelos peregrinos que iam em direção às festas cultuais no Templo de Jerusalém. Cada um destes Salmos tem semelhantemente o título de "Cântico de romagem" ou "Cântico das Subidas". Segundo Marcia Regina Correa, citando Schwantes, “[...] Estes salmos foram entoados por muitas gerações de peregrinos e judaístas devotos, pessoas simples do povo. Embora não podemos fixar uma data para os salmos da subida, o que se pode deduzir é que várias gerações fizeram parte da formulação deste grupo de salmos" (CORREA, 2014, p. 19-20).

${ }^{4}$ Pierre Teillard de Chardin (1881-1955) era um jesuíta francês, teólogo, geólogo e paleontólogo, que tentou construir uma visão integradora entre ciência e teologia. Em 1942, quando estava exilado no Oriente, escreveu algumas meditações sobre a felicidade.
} 
Para Chardin, no mundo material, todos os seres vivos se movimentam na busca do bem-estar. Nessa perspectiva, os seres humanos também caminham na construção de um bem-estar possível a que ele chama de felicidade. Tal posição se contrapõe ao pensamento fluente entre seus contemporâneos, em meados do século $\mathrm{XX}$, uma vez que entende que o debate sobre o tema em seu tempo histórico é permeado pela conclusão de que essa busca é inútil (CHARDIN, 2005, p. 10-11). Como ele mesmo afirma: "É diretamente contra esse ceticismo relativista e, em última instância, pessimista de nossos contemporâneos que [...] me proponho falar [...]" (CHARDIN, 2005, p. 12).

Para o teólogo, "O homem feliz [...] é aquele que, sem buscar diretamente a felicidade, encontra inevitavelmente a alegria como acréscimo, no ato de alcançar a plenitude e no último recôndito de si mesmo, adiante de si" (CHARDIN, 2005, p. 20). Esse crescimento em direção ascendente, Chardin observa na natureza em geral e considera que se baseia nos princípios da teoria da Evolução e das conquistas científicas da Física e da Biologia de seu tempo.

Para Chardin, o movimento ascensional da Vida implica movimentos de felicidade associados a ele, que se traduzem em júbilo e alegria, como expressões de uma realização transcendente. Parece ser a isso que Adélia se referiu na entrevista mencionada acima (PRADO, 2000, p. 35), quando fala da "cristificação" do mundo, onde todas as coisas estão restauradas em Cristo.

Dessa forma, o posicionamento de Adélia, e também de Chardin, é de estreitamento afinado com a teologia cristã, no caso deles, pela origem católica, mas cristã em sua essência mais ampla, admitida por outros segmentos desse posicionamento de fé. Esse fundamento fará parte, de forma recorrente, da composição de muitos poemas adelianos.

Não é difícil supor que tal posicionamento se coloca em franca tensão com as ideias da modernidade, não pela simples conservação de dogmas católicos da poeta, antes, pelo contrário, pela afirmação de um entendimento complexo de mundo, a partir de uma visão religiosa que integra o sagrado ao cotidiano da vida e à relação com o mundo imediato. É o que observa Ana Lúcia Moret, em estudo sobre a poeta:

Ela se coloca no momento anterior ao rompimento entre sagrado e o profano que originou toda uma mentalidade responsável pelo rebaixamento da vida natural e pela valorização da vida superior, considerada mais perfeita, mais pura. Se o homem religioso tradicional se quer diferente do seu "natural" e esforça-se por se fazer segundo uma imagem ideal, o homem religioso de Adélia Prado concebe as miudezas de sua vida terrena como parte integrante e significativa do processo de aprendizagem, no qual a morte não representa um rompimento, mas a passagem para outro nível (sem se fazerem aí comparações qualitativas) (MORET, 1993, p. 150).

Percebe-se, assim, que a visão religiosa de Adélia - de inspiração, pode-se pensar, franciscana - equaciona um movimento dialético entre a visão tradicional cristã e os rompimentos com os valores desta visão, evidenciados no pensamento da modernidade, sobretudo pós-século XIX, o que não deixa de provocar reações de resistência, às vezes de rechaço ou até de curiosidade. Como observa Afonso Romano de Sant'Anna, a meio caminho de cada uma dessas reações: "Adélia disse, de novo, que acredita na ressurreição da carne. Perguntei-lhe como, com que corpo? Velho? Antigo? Ela acha que é com esse mesmo, mas, bonito. Acredita mesmo" (SANTANNA, 1987). A poeta e sua obra são cheias de ressurreições, de aparente feição católica, mas para além de dogmas simplistas.

Um dos poemas de Bagagem também evidencia a adesão da lírica adeliana às proposições

https://periodicos.unifap.br/index.php/letras

Macapá, v. 8, n. 3, $2^{\circ}$ sem., 2018 
da fé cristã, trazendo uma feição dialógica relacionada mais uma vez a Francisco de Assis:

Um salmo

Tudo que existe louvará.

Quem tocar vai louvar, quem cantar vai louvar, o que pegar a ponta de sua saia e fizer uma pirueta, vai louvar. Os meninos, os cachorros, os gatos desesquivados, os ressuscitados, o que sob o céu mover e andar vai seguir e louvar.

O abano de um rabo, um miado, u'a mão levantada, louvarão.

Esperai a deflagração da alegria. A nossa alma deseja, o nosso corpo anseia o movimento pleno: cantar e dançar TE-DEUM (PRADO, 2015, p. 31-32).

Neste salmo adeliano, tudo o que existe, natural e culturalmente, é chamado a louvar a Deus. Mais do que isso, há uma constatação de que tudo o que existe tem o propósito de alcançar um "movimento pleno" dirigido a Deus, TE-DEUM (A Ti, Deus), que deflagrará também a alegria. O poema se estrutura segundo as características mesmo de um salmo judaico, sobretudo por meio dos paralelismos dos versos. O primeiro verso traz a tônica da formalidade dos poemas bíblicos, mas logo essa formalidade é quebrada pela expressão que, embora em estrutura paralela, contrapõe o tom formal, com a adoção do caráter de oralidade da expressão recorrente "vai louvar", como a indicar uma atualização da proposição bíblica, reforçada pelo diálogo com a voz de Francisco de Assis, que ecoa no dizer do sujeito lírico.

Sobre o viés franciscano da obra de Adélia, Augusto Massi aponta:

Se refletirmos sobre esta filiação franciscana, veremos que ela apresenta uma profunda correspondência com a poesia modernista brasileira, cujo traço predominante é a postura antirretórica e o despojamento de linguagem, tão visível na lição cultivada por Manuel bandeira, a quem Murilo Mendes não hesitou em definir como "um franciscano da poesia" (MASSI, 2015, p.499).

Massi advoga, assim, que a associação da lírica modernista tomando traços franciscanos como chave interpretativa é um terreno espinhoso, mas a formula em relação aos versos de alguns poetas, como Jorge de Lima e Murilo Mendes, e em relação a certo hibridismo presente em Vinícius de Moraes: "Não haveria uma raiz comum nesta dinâmica da nossa formação social? Um catolicismo que deseja fundir o regional no universal, o terreno no místico?” (MASSI, 2015, p. 500).

Nesse sentido, Adélia Prado, para esse pesquisador de sua obra, seria considerada não isoladamente, mas ligada possivelmente a um desdobramento de uma face do nosso Modernismo, que dialoga de forma muito profícua com elementos da fé cristã, sobretudo a mística fransciscana, elementos muito enraizados na cultura brasileira de um modo geral, que 
vincula a mística católica às realidades mais corriqueiras do cotidiano.

\section{REFERÊNCIAS}

ANDRADE, Carlos Drummond de. Poesia e prosa. Rio de Janeiro: Nova Aguilar, 1988.

AQUINO, Tomás de. Suma teológica. Disponível em: < https://sumateologica.files.wordpress.com/2017/04/suma-teolc3b3gica.pdf $>$ Acesso em: 10/ set. 2018.

BÍBLIA SAGRADA. Tradução para o Português por João Ferreira de Almeida. Revista e atualizada no Brasil. 2. ed. Barueri: Sociedade Bíblica do Brasil, 1993.

BOFF, Leonardo. Símbolos franciscanos, "O cântico das criaturas". Franciscanos, São Paulo. Disponível em: < http://franciscanos.org.br/?page id=3124>. Acesso em: 25 maio. 2017.

CHARDIN, Pierre Teilhard de. Sobre a felicidade; sobre o amor. Tradução de Martha Gouveia da Cruz. Campinas: Verus, 2005. p. 9-48.

CORREA, Marcia Regina. Os salmos da subida. In: ANAIS da V Jornada Interdisciplinar de Pesquisa em Teologia e Humanidades (JOINTH). Curitiba: PUC-PR, 2014. v. 3, n. 1, 2014. p. 14-25. Disponível em: <https://pt.scribd.com/document/358035929/5jointh14938> Acesso em: 20 mar. 2018.

DAVIS, John D. Dicionário da Bíblia. Tradução de J.R. Carvalho Braga. 4 ed. Rio de Janeiro: Casa Publicadora Batista, 1973.

HERÁCLITO. Heráclito. In: ANAXIMANDRO; PARMÊNIDES; HERÁCLITO. $\boldsymbol{O} \boldsymbol{s}$ pensadores originários. Introdução de Emmanuel Carneiro Leão. Traduções de Emmanuel Carneiro Leão e Sérgio Wrubblewski. 4. ed. Bragança Paulista: Universitária São Francisco, 2005. p. 57-93.

HUAMÁN, José Francisco Navarro. Oráculos de março. In: IMS. Cadernos de Literatura Brasileira: Adélia Prado. São Paulo, n. 9, jun. 2000. p. 21-39. Um dos entrevistadores de Adélia Prado pelo IMS.

LAUAND, Jean. A mística da poesia: de Heráclito a Adélia Prado. International Studies on Law and Education, CEMOrOc-Feusp/JI-Universidade do Porto. 7 jan-abr. 2011. Disponível em: <http://www.hottopos.com/isle7/55-68Jean.pdf> Acesso em 16 set. 2018.

MASSI, Augusto. Móbile para Adélia. Posfácio. In: PRADO, Adélia. Poesia reunida. Rio de Janeiro: Record, 2015. p. 495-526.

MORET, Ana Lúcia. Tradição e modernidade na obra de Adélia Prado. Dissertação de Mestrado. Orientação de Iumna Maria Simon. Campinas: Departamento de Teoria Literária/UNICAMPI, 1993. Disponível em: < http://repositorio.unicamp.br/jspui/handle/REPOSIP/269889> Acesso em: 29 ago. 2018.

PRADO, Adélia. O poder humanizador da poesia. TV Câmara. Programa Sempre um papo. Cultura para a Educação, 2008. Disponível em: < $\underline{\text { https://www.you- }}$ tube.com/watch?v=sisSlTXY6bM $>$ Acesso em: 03 jan. 2017.

PRADO, Adélia. Oráculos de março. In: Cadernos de Literatura Brasileira: Adélia Prado, São Paulo, n. 9, p. 21-39, jun. 2000. Entrevista concedida por Adélia Prado a um conjunto de especialistas convidados pelo Instituto Moreira Salles.

PRADO, Adélia. Poesia reunida. Rio de Janeiro: Record, 2015.

SALOMÃO. Margarida. Prefácio. In: PRADO, Adélia. Bagagem. Rio de Janeiro: Imago, 1976. p. 9-16.

SANT'ANNA, Affonso Romano. Drummond, Adélia e Guilherme. Rascunho. Curitiba, 
n. 177, nov. 1987. Disponível em: < http://rascunho.com.br/drummond-adelia-guilherme/> Acesso em: 29 ago. 2018.

SILVA, Domingos Carvalho da. Uma teoria do poema. Brasília: Thesaurus, 1986. 